\title{
OPEN Effect of earthworm Eisenia fetida epidermal mucus on the vitality and pathogenicity of Beauveria bassiana
}

\author{
Xibei Zhou, Wulong Liang, Yanfeng Zhang, Zhumei Ren \& Yingping Xie
}

Beauveria bassiana is one of the most widely studied and used entomopathogenic fungus as biopesticide. In the biological control of pests, B. bassiana will persist in the soil after application, and will inevitably contact with earthworms, especially the epigeic earthworm species. So, what are the effects of earthworm and its epidermal mucus on the activity of $B$. bassiana? We employed the epigeic earthworm Eisenia fetida, B. bassiana TST05 strain, and the insect Atrijuglans hetaohei mature larvae to study the impact of earthworm epidermal mucus on the vitality and pathogenicity of $B$. bassiana to insect. Methods included scanning electron microscope observation, detection of spore germination, fungal extracellular enzyme activity, and infection testing to $A$. hetaohei. The results showed that the $B$. bassiana spores may attach to the cuticle of $E$. fetida but they could be covered by the epidermal mucus and became rough and shrunken. After treatment with the epidermal mucus, the spore germination and extracellular enzymes of $B$. bassiana was significantly inhibited. Inoculation of $A$. hetaohei larvae with a mixture of $B$. bassiana and mucus showed that the mucus could reduce the pathogenicity of $B$. bassiana to the insect, resulting in a slower disease course and lower mortality. It was concluded that the epidermal mucus of the earthworm $E$. fetida can inhibit the activity of $B$. bassiana, as well as the infectivity and pathogenicity of fungus to target insects. However, after treatment with epidermal mucus the surviving $B$. bassiana still had certain infectivity to insects. This is of great significance for the application of $B$. bassiana in biological control of pests.

Beauveria bassiana, as a broad-spectrum entomopathogenic fungus, can infect more than 700 species of insects in 149 families of 15 orders and more than ten species of Acarina. It is also one of the most widely studied and used entomopathogenic fungi ${ }^{1,2}$. When $B$. bassiana infects insects, spores can adhere to the insect body surface through hydrophobic interactions. The spores absorb moisture from the insect surface to germinate and produce germ tubes. A variety of extracellular enzymes, such as chitinase and protease, are secreted from the tip of germ tubes, which can dissolve chitin and protein in the insect cuticle. The germ tubes extend continuously and penetrate into the insect cuticle and then enter the insect coelom. With the propagation of blastospores, the hyphae of B. bassiana penetrate the cuticle of insect and invade the blood cavity, infecting blood cells and internal organs. Arthrospores germinated and produced large amounts of toxins. When spores and hyphae develop to a certain number, the spores begin to decline and the hyphae increase gradually. The hyphae invade the body fat, digestive tract, Malpighian tubules, ganglion and trachea, as well as other tissues and organs, and can destroy the cells and lead to death of the insect ${ }^{3,4}$.

Fungus $B$. bassiana can persist in soil and play an important role in the regulation of insect populations in soil under natural conditions ${ }^{5}$. Fungus $B$. bassiana is widely used as a biopesticide to control pests in farmland, orchards, vegetable fields and forest ${ }^{6-8}$. After application, B. bassiana can enter the soil and persist for a long time. It plays an important role in the control of pests ${ }^{9,10}$.

Earthworms are ubiquitous in farmland, orchards, vegetable gardens and woodlands and play important ecological functions in soil, such as loosening soil, improving aggregate structure, regulating soil acidity, decomposing organic matter in the soil, and improving soil fertility ${ }^{11,12}$.

Earthworms can secrete mucus from their epidermal secreting cells. The epidermal mucus together with coelomic fluid discharged from the dorsal pores forms a mucus layer over their body surface. The earthworm mucus is a water-soluble mixture of low molecular weight carbohydrates, aminoacids, glycosides and glycoproteins. Among them, mucus proteins are the basic components of innate immunity ${ }^{13-16}$. The epidermal mucus can keep 
the skin moist, ensure normal breathing, and play a lubricating role in the movement of earthworms. Epidermal mucus is also an important immune barrier for earthworms against pathogenic microorganisms in soil ${ }^{17,18}$. Earthworms can affect the species structure in soil by interacting with other organisms. It has been reported that earthworm epidermal mucus can inhibit some bacteria and affect the activities and abundance of bacteria in soil ${ }^{19,20}$. Mucus also has an obvious effect on the physiological function of several nematodes inhabiting soil and can regulate the quantity and distribution of these nematodes ${ }^{10,21,22}$.

However, it has not been reported whether the earthworm epidermal mucus affects the activity of B. bassiana. In the biological control of pests, $B$. bassiana will persist in the soil after application, and will inevitably contact with earthworms, especially the epigeic earthworm species, e.g. E. fetida. So, what are the effects of earthworm and its epidermal mucus on the activity of B. bassiana? We hypothesized that the presence of the earthworm epidermal mucus might have an antifungal effect on $B$. bassiana, thereby reducing their fitness. The aim of the present study was to investigate the impact of the earthworm epidermal mucus on B. bassiana biological control efficacy.

We employed a model system composed of earthworm E. fetida (Savigny) (Opisthopora: Lumbricidae), $B$. bassiana strain TST05 and the mature larvae of A. hetaohei Yang (Lepidoptera: Heliodinidae). In which, E. fetida is an epigeic species, and is the most commonly species used for composting with widespread distribution ${ }^{22}$. The strain B. bassiana TST05 is a highly pathogenic strain that was originally isolated in 2009 by our laboratory from the naturally infected overwintering larvae of Carposina sasakii (Matsumura) (Lepidoptera: Carposinidae) in the soil of apple orchards in Xiangfen County, Shanxi Province, China. On the basis of morphological identification, the strain was identified by molecular technology. After BLAST comparison, the homology of TST05 with $B$. bassiana (Accession No. JN713138, HQ444271) and Cordyceps bassiana (Accession No. AJ564808) in GenBank was $99 \%$, and the support rate was $100 \%$ on the same branch of the evolutionary tree ${ }^{23}$. Therefore, the TST05 strain was identified as B. bassiana. The biological characteristics of the B. bassiana TST05 strain, pathogenicity to host insects, persistence in soil, and compatibility with chemical insecticides were studied in previous researches ${ }^{24-26}$. At the same time, the strain was deposited in the China General Microbial Species Conservation and Management Center (Beijing, China) under storage number CGMCC4526. The mature larvae of A. hetaohei Yang (Lepidoptera: Heliodinidae) were selected as the target insects infected by B. bassiana strain TST05. It is an important pest of walnut fruit in northern China. The insect produces one generation a year, and its larvae bore into walnut fruit to feed on the pulp, which makes the walnut fruit lose its commercial value. The newly hatched larvae bore into the fruit in May and develop to maturity in late August. They drill out of the fruit and fall into the soil layer to live through the winter and cocoon and pupate. In the early summer of the next year, the adults emerge and bore out of the soil and then mate and lay their eggs in walnut trees. Under natural conditions, larvae are often infected by entomogenous fungi such as $B$. bassiana in soil. The biological control of $A$. hetaohei using B. bassiana and other entomopathogenic fungi has attracted much attention ${ }^{27}$. An infection test of $B$. bassiana strain TST05 on A. hetaohei and the application of a strain preparation in walnut orchard soil were carried out in prior study to control the mature larvae, and high infection mortality was achieved ${ }^{28}$. Therefore, the mature larvae of $A$. hetaohei were selected as the target insects infected by B. bassiana strain TST05 in this study. In addition, after entering the soil, the mature larvae of $A$. hetaohei can exist together with earthworm E. fetida and $B$. bassiana TST05 strain for 8-9 months. Thus, it is a typical insect in the walnut orchard soil environment.

This study provides a reference for understanding the impact of earthworm epidermal mucus to B. bassiana in the activity and pathogenicity to the insects. It is significant for the application of B. bassiana as a biopesticide in the field.

\section{Results}

Attachment of $\boldsymbol{B}$. bassiana to the body surface of $\boldsymbol{E}$. fetida. Under SEM, it was observed that $B$. bassiana spores often adhere to the intersegmental furrows between the segments, annulus on the segments, grid-like structures between the annuli, and those around the stomata of E. fetida (Fig. 1). As time progressed, the attached spores of $B$. bassiana exhibited obvious changes in morphology. After $1 \mathrm{~h}$ of incubation, the attached spores remained smooth, round and plump in shape (Fig. 1A). After $3 \mathrm{~d}$, the spores changed to rough and uneven because of the earthworm epidermal mucus covering (Fig. 1B). After $7 \mathrm{~d}$, the spores had shrunken and shriveled (Fig. 1C). Some spores were also observed near the stomata, and they were also covered with the earthworm epidermal mucus (Fig. 1D). In observation, although spore attachment, morphological change, and covering with the earthworm epidermal mucus were observed, spore germination was not seen on the body surface of the earthworms.

Effect of $E$. fetida epidermal mucus on spore germination of $B$. bassiana. After incubating with solutions of epidermal mucus, the colonies of $B$. bassiana exhibited obvious differences after treatment with the earthworm epidermal mucus (Fig. 2). In the control group that was not incubated with E. fetida epidermal mucus, $B$. bassiana grew considerably more colonies on the plate (Fig. 2A), with 14.20 colonies on average (Fig. 3). In contrast, less B. bassiana grew in the groups treated with E. fetida epidermal mucus. As the concentration of E. fetida epidermal mucus increased, the number of colonies gradually decreased (Fig. 2B-F). In total, an average of 5.60 fungal colonies were noted on the culture plates that were inoculated spores treated with $1.25 \mathrm{mg} /$ $\mathrm{mL}$ E. fetida epidermal mucus solution, a decrease of $60.6 \%$ (Figs. $2 \mathrm{~B}, 3$ ). In comparison, the number of fungal colonies decreased to an average of 2.20 upon treatment with $2.50 \mathrm{mg} / \mathrm{mL}$ E. fetida epidermal mucus solution, a decrease of $84.5 \%$ (Figs. 2C, 3). The average number of colonies was only 0.40 upon treatment with $5.00 \mathrm{mg} / \mathrm{mL}$ epidermal mucus solution, a decrease of $97.2 \%$ (Figs. 2D, 3). An extreme change was observed upon treatment with $10.00 \mathrm{mg} / \mathrm{mL}$ and $20.00 \mathrm{mg} / \mathrm{mL}$ E. fetida epidermal mucus solutions. Specifically, no colonies grew on the culture plates (Figs. 2E,F, 3). Statistical analysis showed that the number of B. bassiana colonies significantly 

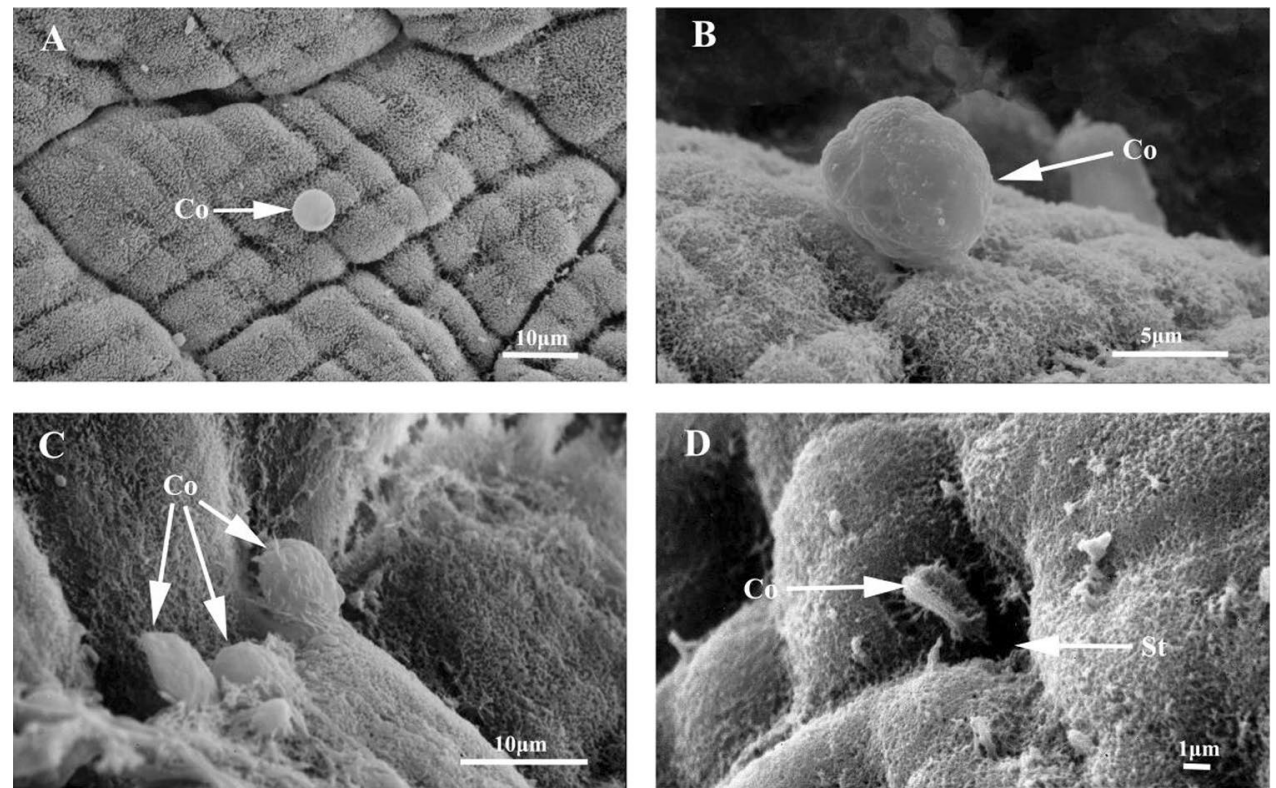

Figure 1. SEM photos of B. bassiana spores attachment to the body surface of the earthworm E. foetida. (A) The grid-like structures on the body segments of the earthworm E. foetida and the attached B. bassiana spores. (B) the attached B. bassiana spores were wrapped by the epidermis mucus of the earthworm E. foetida. (C) the attached B. bassiana spores changed into shrunk and shriveled. (D) the B. bassiana spores attached near the stomata and covered with the epidermis mucus of the earthworm E. foetida. Co: B. bassiana spores; St: Stomata of the earthworm E. foetida.
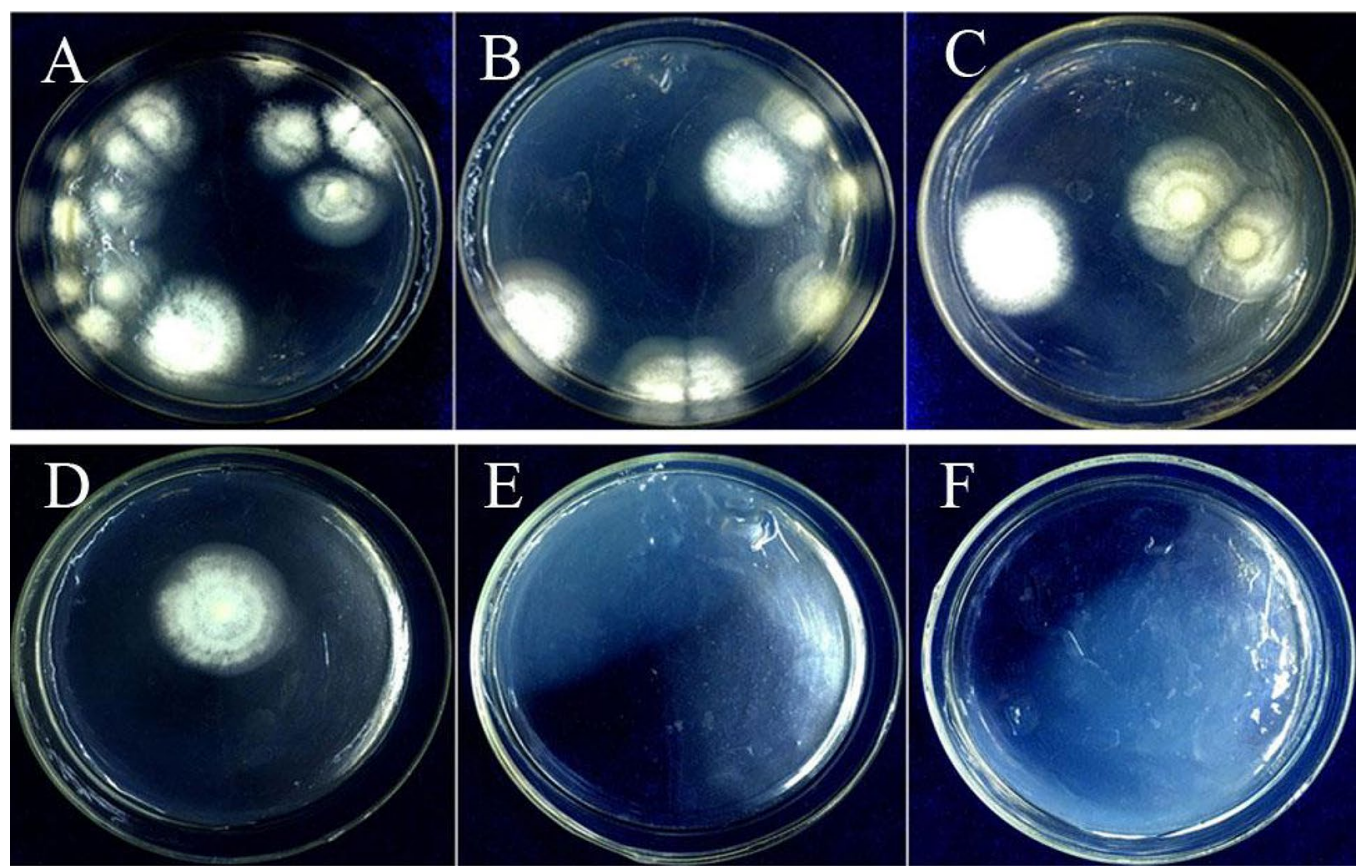

Figure 2. On the plate culture media, the comparison of the spore germination and colony growth of $B$. bassiana treated with the epidermis mucus of the earthworm E. foetida in different concentrations. (A): Control group, in which, before inoculation, the B. bassiana spores were not treated with the earthworm epidermis mucus. (B-F): Treatment groups, in which, before inoculation, the B. bassiana spores were treated with the earthworm epidermis mucus in the concentrations of $1.25 \mathrm{mg} / \mathrm{mL}$ (B), $2.50 \mathrm{mg} / \mathrm{mL}$ (C), $5.00 \mathrm{mg} / \mathrm{mL}$ (D), $10.00 \mathrm{mg} / \mathrm{mL}(\mathbf{E})$, and $20.00 \mathrm{mg} / \mathrm{mL}(\mathbf{F})$, respectively. 


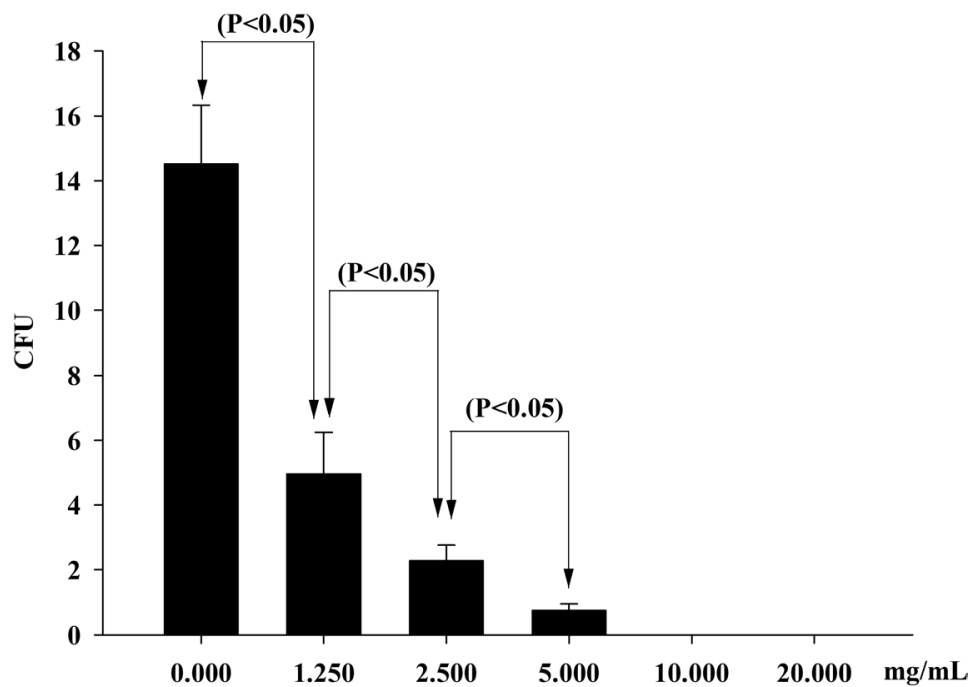

Figure 3. Statistical analysis of the colony quantities of B. bassiana treated with the epidermis mucus of the earthworm E. foetida in different concentrations.

differed between the treatment and control groups. With the increase in the E. fetida epidermal mucus concentration, the number of colonies decreased significantly (Fig. 3). Therefore, the E. fetida epidermal mucus had a significant inhibitory effect on $B$. bassiana spore germination. This inhibitory effect was correlated with the concentration of $E$. fetida epidermal mucus. When the concentration of earthworm epidermal mucus was more than $10.00 \mathrm{mg} / \mathrm{mL}$, the inhibitory effect on B. bassiana spores reached $100 \%$. A significant Linear correlation was found between earthworm mucus concentration and fungal colony number as follows: $\mathrm{Y}=-2.5429 \mathrm{X}+12.653$ $\left(\mathrm{R}^{2}=0.7222\right)$.

Inhibitory effect of $E$. fetida epidermal mucus on extracellular enzyme activity of $B$. bassiana. In this experiment, freeze-dried epidermal mucus powder of E. fetida was added to the culture medium to assess whether the E. fetida epidermal mucus would affect the extracellular enzyme activity of B. bassiana. The results showed that the enzymatic activities of the 4 extracellular enzymes studied significantly changed after treatment (Fig. 4). In the control group without E. fetida epidermal mucus (CK group), the fungal protease (Fig. 4A), lipase (Fig. 4B), chitinase (Fig. 4C), and $N$-acetyl- $\beta$-D-glucosidase (NAG) enzyme (Fig. 4D) activities in the medium all exhibited a similar trend that increased in the first phase and then decreased in the later phase.

In contrast, in the treatment group with E. fetida epidermal mucus added every day (EW group), the enzymatic activities of the subtilisin-like protease, lipase, chitinase and NAG remained at very low levels (Fig. 4A-D). The enzymatic activities of these 4 extracellular enzymes of $B$. bassiana were inhibited by the addition of epidermal mucus to the medium.

In treatment group, which contained E. fetida epidermal mucus added only once at inoculation (EO group), compared with the other two groups, the activities of 4 extracellular enzymes showed different trends. During days 1-4 after inoculation, the enzymatic activities of the 4 extracellular enzymes remained at very low levels (Fig. 4A-D). However, the activities of the 4 extracellular enzymes increased daily from the 4 th day. On the 8 th day, the activities of 4 extracellular enzymes increased significantly.

The effect of $E$. fetida epidermal mucus on the pathogenicity of $B$. bassiana. The results showed that in the treatment group with B. bassiana spores only, after inoculation, the A. hetaohei larvae slowly deepened their body color, and individual larvae began to die on the 3rd day (Fig. 5A1). White hyphae appeared on the surface of the larvae on the 5th day (Fig. 5A2). The dead worms became stiff and surrounded by white hyphae on the 7th day (Fig. 5A3). From 10 to 14th day, the larvae were completely covered with white hyphae and spores (Fig. 5A4,A5). In the treatment group with B. bassiana spore suspension supplemented and earthworm epidermal mucus, the larvae showed slow infection symptoms after inoculation. Their activity decreased on the 3rd day (Fig. 5B1). On the 5th day, the larvae showed symptoms of infection and lesions on the body surface (Fig. 5B2). On the 7th day, the infected larvae died one after another (Fig. 5B3). On the 10th day, white hyphae appeared successively on the surface of larvae (Fig. 5B4). On the 14th day, the larvae were completely surrounded by white hyphae (Fig. 5B5).

After 14 days of continuous observation and mortality statistics, the treatment group with sterilized distilled water only was used to calculate the corrected mortality. The results showed that, there was no significant difference between the treatment group with sterilized distilled water and the treatment group with earthworm epidermal mucus. The mortality of the A. hetaohei larvae treated by B. bassiana spores with E. fetida epidermal mucus was relatively low in the first 5 days. At $3 \mathrm{~d}$ and $5 \mathrm{~d}$, the cumulative corrected mortality of the larvae was $2.247 \pm 1.619 \%$ and $4.560 \pm 2.068 \%$, respectively. In the control group without $E$. fetida epidermal mucus (CK group), the cumulative corrected mortality rate was $11.236 \pm 2.570 \%$ and $47.126 \pm 3.320 \%$, respectively. After 5 
A

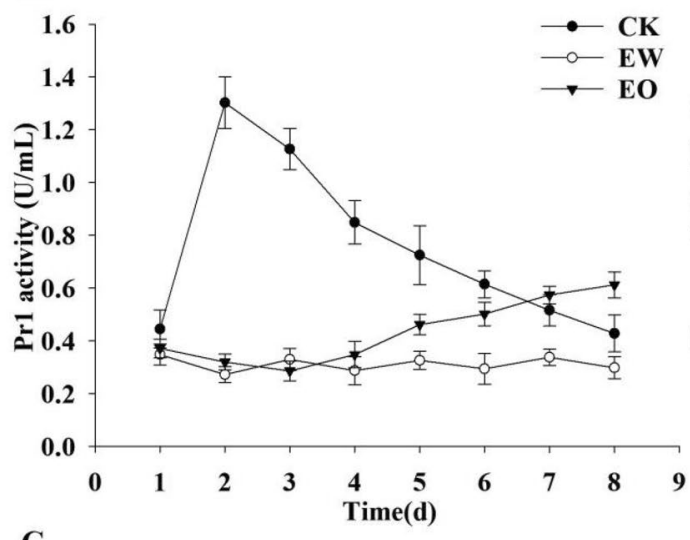

C

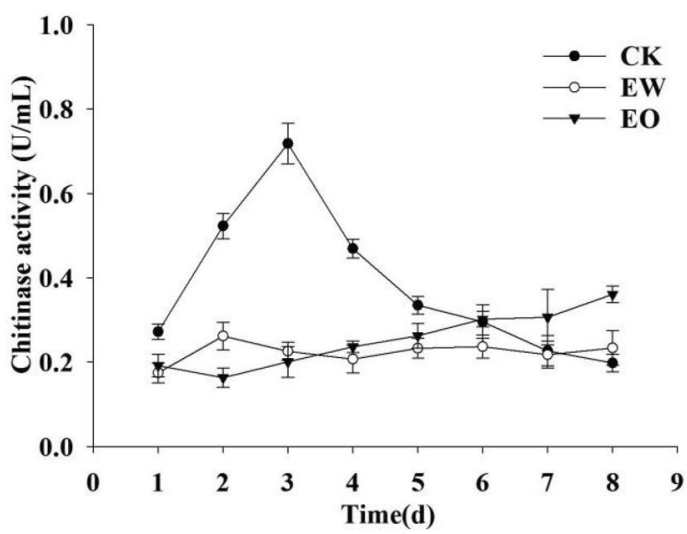

B

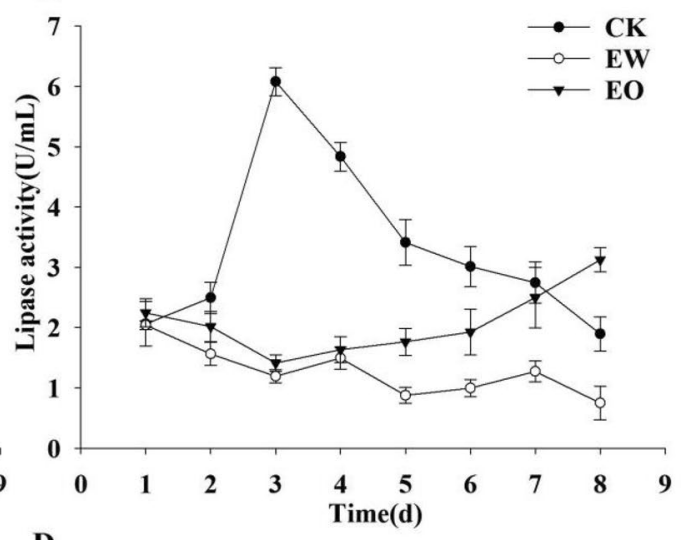

D

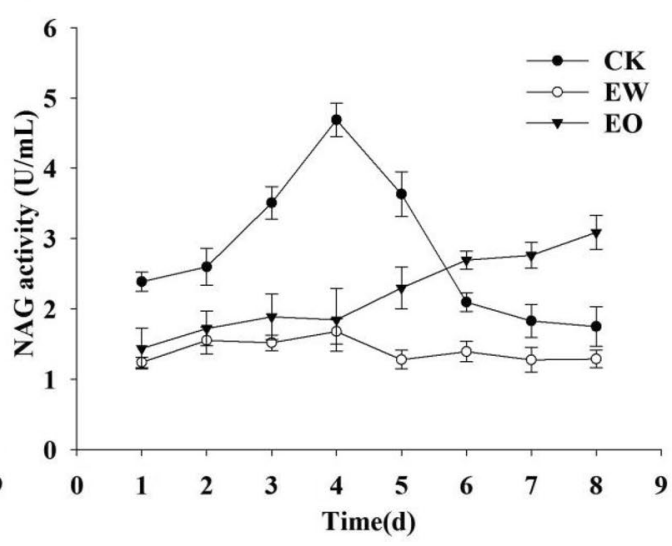

Figure 4. Comparison of the inhibitory effects of the epidermal mucus of the earthworm E. foetida on the 4 extracellular enzyme activities of B. bassiana. (A): subtilisin-like protease, (B): lipase, (C): chitinase, and (D): NAG. CK: the control group, no added the epidermal mucus of the earthworm E. foetida to the liquid medium. EW: treatment group, added the epidermal mucus of the earthworm E. foetida to the liquid medium once before inoculation and replenished the epidermal mucus every day during inoculation. EO: added the earthworm epidermis mucus to the liquid medium only once before inoculation.

$\mathrm{d}$, the mortality rate of larvae in the treatment group increased significantly. At $7 \mathrm{~d}, 10 \mathrm{~d}$, and $14 \mathrm{~d}$, the cumulative corrected mortality of larvae was $10.588 \pm 4.342 \%, 45.238 \pm 4.025 \%$, and $67.901 \pm 3.782 \%$, respectively, while that in the CK group was $74.118 \pm 5.263 \%, 94.048 \pm 4.166 \%$, and $100 \%$, respectively (Fig. 6). The mortality rate of larvae in the treated group was lower than that in the CK group, and the difference was significant. The median lethal time of the larvae in the treatment group of B. bassiana with E. fetida epidermal mucus was $10.664 \mathrm{~d}$, but that in the CK group was $5.537 \mathrm{~d}$. This difference reached significance. This experiment showed that the E. fetida epidermal mucus did have a certain influence on the pathogenicity of $B$. bassiana to the larvae in 2 ways: the mortality rate of larval was reduced and the lethal time of larvae was prolonged. Nevertheless, the surviving $B$. bassiana still maintain certain infectivity to the insect.

\section{Discussion}

The strian B. bassiana is one of the most important entomopathogenic fungi and can persist in soil for many years $^{1,29}$. Earthworms are important and abundant invertebrates in soil and interact closely with other organisms, especially microorganisms, in the soil ${ }^{17,20,30-33}$. In this paper, the effect of the E. fetida epidermal mucus on B. bassiana in fungal vitality and infectivity to insects was studied, and some novel results were obtained.

The main pathway by which $B$. bassiana infects insects is integument infection. The fungal spores must adhere to the cuticle of the insects, germinate, and produce germ tubes and hyphae; then, they penetrate into the insect integument and infect ${ }^{3,34}$. In this study, by using SEM, it was observed that the spores of $B$. bassiana may adhere to the epidermis of $E$. fetida and are often attached at the intersegmental furrows, annulus on the segments, and grid-like structures between the annuli and around the stomata. It is very similar to the characteristics of $B$. bassiana adhesion on insect cuticles ${ }^{24}$. However, the difference is that the adhered spores on the epidermis of the earthworm E. fetida did not germinate, but they could be covered by the earthworm epidermal mucus and change their shape from smooth and plump at first to rough and shrunken and even shriveled. This indicated that $B$. bassiana spores can be attached to the epidermis of earthworms, but it is hard for them to germinate on the epidermis of earthworms. It is speculated that the E. fetida epidermal mucus may play an antifungal role on B. bassiana and cause inactivation of B. bassiana spores. 


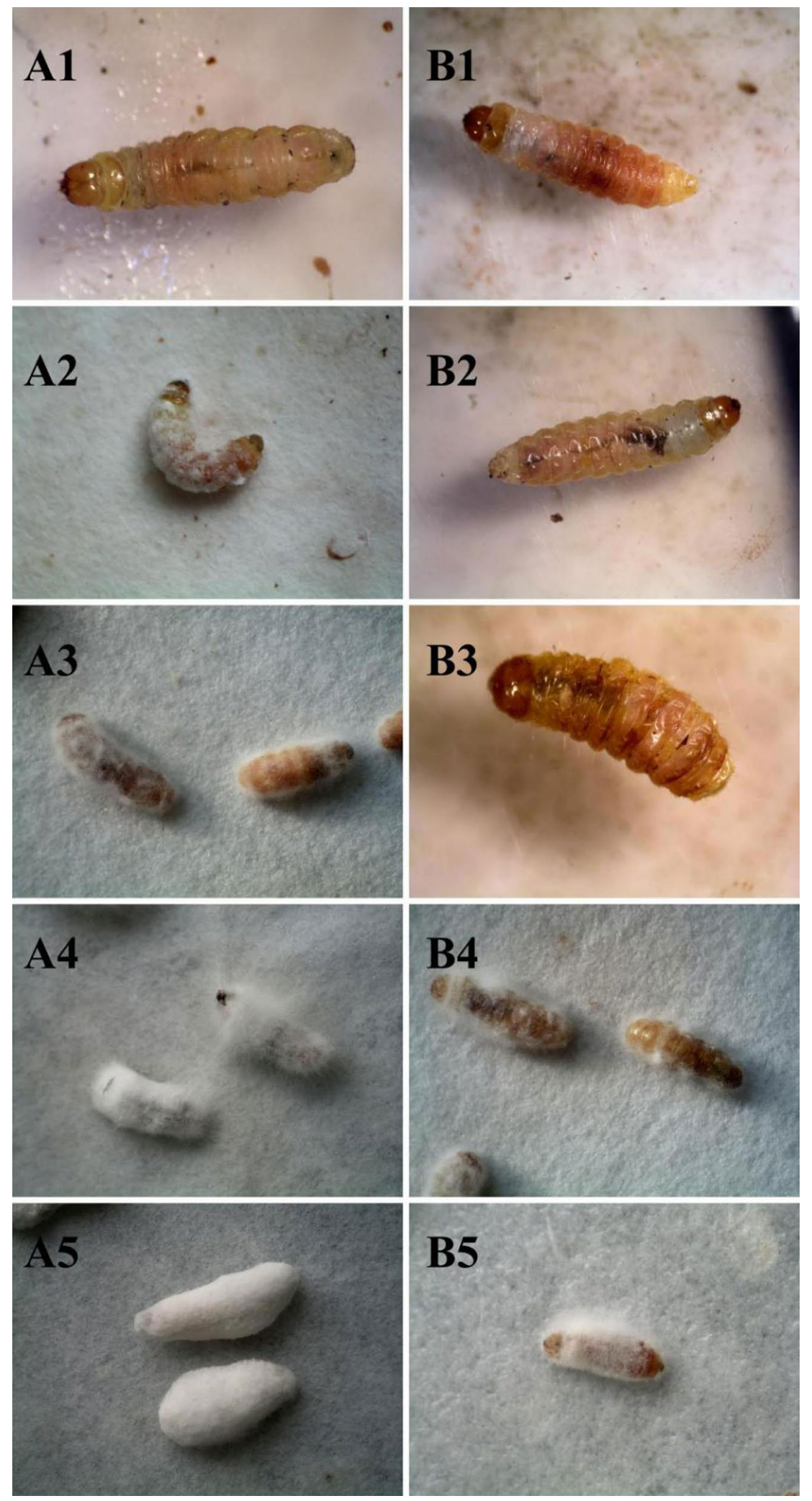

Figure 5. Comparison of the infective symptoms of $A$. hetaohei larvae infected by the B. bassiana treated or not treated with the epidermal mucus of the earthworm E. foetida. (A): treatment group 3, in which, the B. bassiana before inoculation, was not treated with the epidermal mucus of the earthworm E. foetida. (A1-A5) showing the infection symptoms of larvae on the 3rd, 5th, 7th, 10th and 14th days, respectively, after inoculated. (B): treatment group 4 , in which, the B. bassiana before inoculation, was treated with the epidermal mucus of the earthworm E. foetida. (B1-B5) showing the infection symptoms of larvae on the 3rd, 5th, 7th, 10th and 14th days, respectively, after inoculated. 


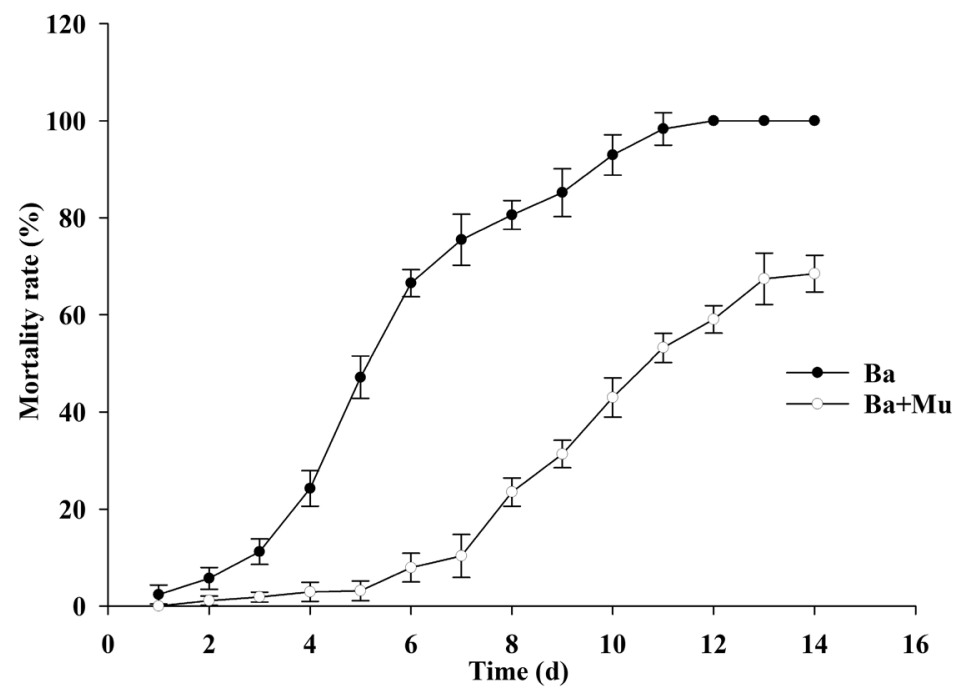

Figure 6. Comparison of the corrected mortality of $A$. hetaohei larvae infected by the B. bassiana treated or not treated with the epidermal mucus of the earthworm E. foetida. Ba: control group, the corrected mortality of $A$. hetaohei larvae were inoculated with the B. bassiana that was not treated with the earthworm epidermis mucus. $\mathrm{Ba}+\mathrm{Mu}$ : the corrected mortality of $A$. hetaohei larvae were inoculated with the B. bassiana that was treated with the earthworm epidermis mucus.

To verify this conjecture, E. fetida epidermal mucus at five concentrations was used to treat spores of B. bassi$a n a$, and their effect on spore germination and colony growth was observed. In this experiment, about $10 \mathrm{mg}$ of mucus lyophilized powder can be obtained per $1 \mathrm{~mL}$ of mucus. It is speculated that the natural concentration of earthworm mucus is about $10 \mathrm{mg} / \mathrm{mL}$. Therefore, $20.00 \mathrm{mg} / \mathrm{mL}, 10.00 \mathrm{mg} / \mathrm{mL}, 5.00 \mathrm{mg} / \mathrm{mL}, 2.50 \mathrm{mg} /$ $\mathrm{mL}$, and $1.25 \mathrm{mg} / \mathrm{mL}$ mucus solution was used to observe the germination of $B$. bassiana spores. The results showed that the E. fetida epidermal mucus could significantly inhibit the spore germination of B. bassiana in a dose-dependent manner. It was reported that the E. fetida epidermal mucus is composed of carbohydrates, lipids, peptides, proteins, amino acids and other molecules ${ }^{13,15,16,35}$, and some mucopolysaccharide and protein components have antibacterial effects ${ }^{16,36}$. Wang ${ }^{16,37}$ isolated some antimicrobial peptides and polysaccharide from the surface mucus of earthworms and demonstrated that these antimicrobial peptides and lectins have obvious inhibitory effects on Escherichia coli and other bacteria. Thus, it is very likely that the inhibitory effect of the epidermal mucus of the earthworm E. fetida on B. bassiana is also from the related components of the antimicrobial peptides and some mucopolysaccharides. However, the compositions of the E. fetida epidermal mucus and their antimicrobial components remain to be further studied.

In the process of $B$. bassiana invading the insect cuticle, in addition to the mechanical pressure of fungal penetration to the insect cuticle, degradation to the insect cuticle by extracellular enzymes secreted by the fungus plays an important role ${ }^{38,39}$. This is because the cuticle of the insect body wall is composed of the epicuticle and protoepidermis (outer epidermis and inner epidermis), and the upper epidermis includes the wax protecting layer, wax layer and cuticle seminal layer. The insect epidermis consists of an epicuticle and procuticle. The epicuticle includes the cement layer, wax layer and cuticulin layer from external to internal, and the procuticle is mainly composed of chitin and protein. Additionally, extracellular protease, chitinase and lipase are secreted by $B$. bassiana to degrade protein, chitin and ester of the insect cuticle. The activity of extracellular enzymes of B. bassiana is usually considered an important index to detect its infectivity to host insects ${ }^{40,41}$. In fact, these four groups of extracellular enzymes secreted by B. bassiana belonging to extracellular proteases, chitinases and lipases which, are usually considered to be secreted by B. bassiana in degrading protein, chitin and ester of the insect cuticle. The exact number of enzymes in each of four groups could be further estimated by mining the known genomes of $B$. bassiana species. This problem may need further study.

In this study, E. fetida epidermal mucus lyophilized powder was added to liquid medium every day in the treatment group EW, and the E. fetida epidermal mucus lyophilized powder was only added once at the beginning of culture in the treatment group EO. It was found that during incubation of B. bassiana, the epidermal mucus of the earthworm E. fetida did have a significant inhibitive effect on the 4 fungal extracellular enzymes (subtilisinlike protease, lipase, chitinase, and NAG), and the inhibitive effect could remain for a period of time. Therefore, it is suggested that the epidermal mucus of $E$. fetida can inhibit $B$. bassiana not only for spore germination but also for extracellular enzyme secretion. However, if $B$. bassiana is no longer exposed to the newly secreted $E$. fetida epidermal mucus, the inhibition effect will gradually decrease.

Shapiro Ilan and Brown (2013) found that B. bassiana in soil in which the earthworm Lumbricus terrestris (L.) has been present could still infect Galleria mellonella (L.) larvae. However, the specific effect of the earthworm epidermal mucus on $B$. bassiana infection was not studied. To verify whether the E. fetida epidermal mucus had an effect on the pathogenicity of $B$. bassiana, the larvae of $A$. hetaohei were inoculated with $B$. bassiana spores that were treated with the E. fetida epidermal mucus in advance. The results showed that the E. fetida epidermal 
mucus could truly reduce the pathogenicity of $B$. bassiana to the insect. It could result in a slower disease course and a lower mortality of the larvae during infection. The practical data showed that within $5 \mathrm{~d}$, the mortality rate of the larvae infected by $B$. bassiana in the group treated with E. fetida epidermal mucus was much lower than that of the CK group, but it increased rapidly after $5 \mathrm{~d}$. The mortality rate of the treatment group increased from $3.45 \%$ on the 7 th day to $41.67 \%$ on the 10 th day, but it reached $91.67 \pm 3.85 \%$ in the CK group. The mortality rate of the treatment group at $14 \mathrm{~d}$ was $65.43 \pm 6.78 \%$, while it reached $100 \%$ in the CK group. Moreover, the median lethal time of $B$. bassiana to the larvae in the group treated with the E. fetida epidermal mucus was $10.322 \mathrm{~d}$ in the treatment group, but it was $5.496 \mathrm{~d}$ in the CK group. Therefore, although the pathogenicity of $B$. bassiana to the insect $A$. hetaohei was affected by the epidermal mucus of the earthworm $E$. fetida and was reduced in infectivity to the insect, those $B$. bassiana spores that survived in the treatment with $E$. fetida epidermal mucus still maintained certain infectivity to the insect. In addition, the inhibitory effect of the E. fetida epidermal mucus on B. bassiana can gradually be relieved after 5-7 d with loss of the active component from the E. fetida epidermal mucus.

\section{Conclusions}

As mentioned above, the experiment using the epidermal mucus of the earthworm E. fetida and fungus $B$. bassiana indicated the following conclusion: the epidermal mucus secreted by E. fetida has a significant inhibitory affect on the vitality and pathogenicity of $B$. bassiana. The inhibitive effect includes limiting fungal spore germination, reducing fungal extracellular enzyme secretion and activity, and weakening fungal infectivity and pathogenicity, which caused a slower infection and less mortality of the target insect. These inhibitory effects are interrelated with the concentration and extension time of the epidermal mucus of $E$. fetida. Nevertheless, those B. bassiana spores surviving after treatment with E. fetida epidermal mucus still maintain a certain infectivity to the target insect. When B. bassiana is used as a biological insecticide, the application methods include spraying, dusting or directly applying into the soil. Whichever method is used, it will eventually stay in the soil and contact with earthworms. Previous studies did not consider the effect of earthworm epidermal mucus on B. bassiana. Our study found that the earthworm epidermal mucus has a certain inhibitory effect on $B$. bassiana, including inhibiting spore germination and reducing the pathogenicity to insects. This finding is very important for applying $B$. bassiana in the biological control of insects. However, it is necessary to study the antifungal mechanism of the epidermal mucus of the earthworm E. fetida to B. bassiana.

Earthworms live in an environment with a variety of microorganisms. In order to cope with changing environmental conditions, earthworms require highly responsive stress mechanisms. It has been reported that the expression of immune-related earthworm cellulase in Eisenia andrei was up-regulated after treatment with Bacillus subtilis and Escherichia coli ${ }^{42}$. It was also reported that the expression of cellulase, Lumbrokinase, lysozyme, HSP70 and other immune-related proteins in E. fetida were up-regulated after treatment with $E$. coli ${ }^{43}$. Under the stimulation of Saccharomyces cerevisiae, the expression of pattern recognition receptor CCF (coelomic cytolytic factor) and lysozyme was up-regulated in E. andrei $i^{44}$. Earthworm epidermal mucus is the first defense line of its innate immunity. Earthworms epidermal will secrete a large amount of mucus in response to a stimulus, and form a mucus film wrapped in the surface of the earthworm, which has a protective effect on the earthworm ${ }^{20,22}$. However, it is not reported whether the genes related to innate immunity and mucus secretion of earthworms will change their expression after the earthworms are treated with B. bassiana. Earthworm epidermal mucus is also a complex of many components and the secretion of mucus should be involved by many genes, so it is a subject worthy of further study in the future.

\section{Materials and methods}

Earthworm, fungi and insects. Earthworm E. fetida were obtained from the earthworm breeding base in Baiyangdian, Hebei, China and raised in a laboratory at $20^{\circ} \mathrm{C}$ with $70 \%$ soil humidity. Adult clitellate earthworms of similar body size were selected for this study.

The B. bassiana TST05 strain was cultivated in the laboratory at $25^{\circ} \mathrm{C}$ with $75 \%$ relative humidity (RH), and fungal conidia were collected for the study. Two media were used in the experiments described below: (1) B. bassiana rejuvenation: Potatoes $200 \mathrm{~g}$, Glucose $20 \mathrm{~g}$ (Tianjin FengChuan chemical reagent Technology Co., $\mathrm{Ltd}$ ), Agar $20 \mathrm{~g}$ (Beijing solab Technology Co., Ltd), cuticle powder of target insects $5 \mathrm{~g}$, Distilled water $1000 \mathrm{~mL}$, $\mathrm{pH}$ value of the natural ${ }^{45}$. (2) Potato Dextroxa Agar (PDA): Potatoes $200 \mathrm{~g}$, Glucose $20 \mathrm{~g}$ (Tianjin FengChuan chemical reagent Technology Co., Ltd), Agar $20 \mathrm{~g}$ (Beijing solab Technology Co., Ltd), Distilled water $1000 \mathrm{~mL}$, $\mathrm{pH}$ value of the natural.

The mature larvae of A. hetaohei Yang (Lepidoptera: Heliodinidae) were selected as the target insects infected by B. bassiana strain TST05 in this study. Before the experiment, walnut worm fruit was collected in late August from an experimental walnut orchard in Yuxian County, Shanxi Province, China, and then, the walnut worm fruit was placed in the laboratory in the shade. When the mature larvae naturally drilled out of the fruit, they were collected and placed in a culture dish covered with a wet filter for infection study.

SEM observation of the attachment and germination of $B$. bassiana on the earthworm epidermis. The B. bassiana spores were placed in sterilized distilled water containing $0.1 \%$ Tween 80 and the concentration was $1.0 \times 10^{7}$ spores $/ \mathrm{mL}$. Spore concentration was counted under microscope by using cell counting plate. The immersion method was used for earthworm infection. Earthworm E. fetida sample individuals were steeped for $10 \mathrm{~s}$ into the spore suspension of $B$. bassiana and then maintained at a temperature of $15{ }^{\circ} \mathrm{C}$ for $10 \mathrm{~min}$. Then, earthworms were transferred in a beaker $(500 \mathrm{~mL})$ lined with wet filter paper. Samples were collected at $1 \mathrm{~h}, 3 \mathrm{~d}$ and $7 \mathrm{~d}$ and fixed with $2.5 \%$ glutaraldehyde solution at $4{ }^{\circ} \mathrm{C}$ for $48 \mathrm{~h}$. Then, the earthworm samples were rinsed thrice with $0.2 \mathrm{M}$ phosphate buffer and incubated for $1.5 \mathrm{~h}$ in $1 \%(\mathrm{v} / \mathrm{v})$ osmium tetroxide 
in the same buffer at $4{ }^{\circ} \mathrm{C}$. Then, the samples were washed with $\mathrm{ddH}_{2} \mathrm{O}$ and dehydrated in a series of acetone solutions, which was replaced by liquid carbon dioxide. Finally, the samples were dried using an EMS 850 critical point drying apparatus (Electron Microscopy Sciences, Hatfield, Pennsylvania, USA) and treated with gold spray. The gold-sprayed samples were observed and photographed using a scanning electron microscope (SEM) (model JSM-840, JOL, Ltd., Japan).

Detection of the effect of the E. fetida epidermal mucus on B. bassiana spore germination. The E. fetida individuals were stored in a sterile beaker $(500 \mathrm{~mL})$ with sterilized distilled water. After $30 \mathrm{~min}$ of incubation, the epidermal mucus secreted by the earthworms was collected with sterilized distilled water. Then, a filter membrane was used to remove the bacteria, and the water was removed from the epidermal mucus using a freeze-drying technique. The dry matter of the epidermal mucus of E. fetida was prepared into $1.25 \mathrm{mg} / \mathrm{mL}, 2.50 \mathrm{mg} / \mathrm{mL}, 5.00 \mathrm{mg} / \mathrm{mL}, 10.00 \mathrm{mg} / \mathrm{mL}$, and $20.00 \mathrm{mg} / \mathrm{mL}$ mucus solutions using sterilized distilled water. Sterile distilled water was used instead of the earthworm epidermal mucus solution in the control group. The treatment of each concentration was repeated 3 times.

A suspension of $B$. bassiana spores $(200$ spores $/ \mathrm{mL}$ ) was mixed with different concentrations of the mucus solutions in a $1: 9$ ratio. After incubation at $4{ }^{\circ} \mathrm{C}$ for $2 \mathrm{~h}, 1 \mathrm{~mL}$ of the mixture was smeared onto PDA medium and incubated at $25^{\circ} \mathrm{C}$ for $7 \mathrm{~d}$. The fungal colonies of $B$. bassiana were observed and counted. The experiment was repeated 5 times in each group.

Detection of the inhibitory effect of the $E$. fetida epidermal mucus on the extracellular enzyme activities of $\boldsymbol{B}$. bassiana. Triangle bottles with $40 \mathrm{~mL}$ of the liquid medium $\left(1.5 \mathrm{~g} / \mathrm{L} \mathrm{KH}_{2} \mathrm{PO}_{4}, 0.6 \mathrm{~g} / \mathrm{L}\right.$ $\mathrm{MgSO}_{4}, 0.5 \mathrm{~g} / \mathrm{L} \mathrm{KCl}, 1 \mathrm{mg} / \mathrm{L} \mathrm{FeSO}_{4} \cdot 7 \mathrm{H}_{2} \mathrm{O}, 1 \mathrm{mg} / \mathrm{L} \mathrm{ZnSO} \cdot 7 \mathrm{H}_{2} \mathrm{O}$, and $7.5 \mathrm{~g} / \mathrm{L}$ insect cuticle powder) were sterilized by autoclaving. Then, $1 \mathrm{~mL}$ of the spore suspension $\left(10^{8}\right.$ spores $\left./ \mathrm{mL}\right)$ of $B$. bassiana and $9 \mathrm{~mL}$ of the epidermal mucus solution $(2.5 \mathrm{mg} / \mathrm{mL})$ of E. fetida were mixed and inoculated into the medium. Then, the triangle bottles were put into an oscillator and incubated at $25^{\circ} \mathrm{C}$ for $8 \mathrm{~d}$. During the culture process, the treatment group EW was supplemented with $10 \mathrm{mg}$ earthworm mucus lyophilized powder every day, but the treatment group EO was no longer given epidermal mucus lyophilized powder. In the control group (CK), only spore suspension was added, and the earthworm epidermal mucus solution was replaced by sterile distilled water. The experiment was repeated 5 times in each group.

Preparation of crude enzyme solution: During cultivation, $300 \mu \mathrm{L}$ of culture solution was collected every $24 \mathrm{~h}$ in each triangle bottle. The solution samples were centrifuged at $150,000 \mathrm{~g}$ for $20 \mathrm{~min}$, and the supernatant was the crude enzyme solution. The crude enzyme solution was stored at $-80^{\circ} \mathrm{C}$ before use.

Subtilisin-like protease assay: The method reported by St. Leger was employed $(1987)^{46}$. One unit of protease activity was defined as the amount of enzyme that catalyzes the decomposition of Suc-(Ala) $)_{2}$-Pro-Phe-pNA to produce $1 \mu \mathrm{g}$ nitroaniline per minute.

Lipase assay: The method reported by Silva was employed ${ }^{47}$. One unit of lipase activity was defined as the amount of enzyme that catalyzes the decomposition of fat to produce $1 \mu \mathrm{g} p$-nitrophenol per minute.

Chitinase assay: Chitinase was determined according to the instructions of the Chitinase Kit (BC0825, Beijing Solarbo Science \& Technology Co., Ltd.). One unit of chitinase activity was defined as the amount of enzyme that catalyzes the decomposition of chitin to $1 \mu \mathrm{mol} N$-acetylglucosamine per hour.

NAG assay: NAG was determined according to the instructions of the $\beta$ - $N$-acetylglucosaminidase Kit (A0311-1 Nanjing Jiancheng Bioengineering Institute). One unit of NAG activity was defined as the amount of enzyme that catalyzes the hydrolysis of $1 \mu \mathrm{mol}$ substrate per minute.

Effect of earthworm epidermal mucus on the pathogenicity of $\boldsymbol{B}$. bassiana. Four treatments were set up in the experiment: (1) sterilized distilled water only; (2) sterilized distilled water mixed with earthworm epidermal mucus $(2.5 \mathrm{mg} / \mathrm{mL})$ in a 1:9 ratio; (3) a suspension of $B$. bassiana spores $\left(10^{7}\right.$ spores $\left./ \mathrm{mL}\right)$; (4) a suspension of $B$. bassiana spores $\left(10^{8}\right.$ spores $\left./ \mathrm{mL}\right)$ mixed with earthworm epidermal mucus $(2.5 \mathrm{mg} / \mathrm{mL})$ in a $1: 9$ ratio. Each treatment was repeated 5 times.

The larvae of $A$. hetaohe $i$ were employed as infection insects. The larvae were soaked in the mixture or sterilized distilled water for $5 \mathrm{~s}$ and then placed in a Petri dish lined with wet filter paper and absorbent cotton at the bottom. Forty larvae were placed in each Petri dish, and each experiment was repeated 3 times. The larvae were placed in a $25^{\circ} \mathrm{C}$ incubator, the activity and surface characteristics of larvae were observed every day, and the quantity of dead larvae was counted. After 15 days of observation, the corrected mortality was calculated.

Statistical analyses. Data were analyzed using the SPSS 21.0 statistical software package. ANOVA and Tukey's HSD were performed for statistical analyses.

Received: 18 January 2021; Accepted: 7 June 2021

Published online: 06 July 2021

\section{References}

1. Bartlett, K. \& Lefebvre, C. Field experiments with Beauveria bassiana (Bals.) Vuill. a fungus attacking the European corn borer. Econ. Entomol. 27, 1147-1157 (1934).

2. Feng, M. G., Poprawski, T. J. \& Khachatourians, G. G. Production, formulation and application of the entomopathgenic fungus Beauveria bassiana for insect control: currentstatus. Biocontrol Sci. Technol. 4, 3-34 (1994).

3. Charnley, A. K. Physiological aspects of destructive pathogenesis in insects by fungi: a speculative review. In Symposium SeriesBritish Mycological Society (ed. Anderson, J.M. Rayner, A.D.M. \& Walton, D.W.H.) 229-270 (Cambridge University Press, 1984). 
4. Clarkson, J. M. \& Charnley, A. K. New insights into the mechanisms of fungal pathogenesis in insects. Trends Microbiol. 4, 197-203 (1996).

5. Korosi, G. A. et al. Occurrence and diversity of entomopathogenic fungi (Beauveria spp. and Metarhizium spp.) in Australian vineyard soils. Invertebr. Pathol. 164, 69-77 (2019).

6. Kim, J. C. et al. Long-term storage stability of Beauveria bassiana ERL836 granules as fungal biopesticide. Asia-Pac. Entomol. 22, 537-542 (2019).

7. Lee, S. J. et al. Entomopathogenic Beauveria bassiana granules to control soil-dwelling stage of western flower thrips, Frankliniella occidentalis (Thysanoptera: Thripidae). Biocontrol 62, 639-648 (2017).

8. de Faria, M. R. \& Wraight, S. P. Mycoinsecticides and mycoacaricides: a comprehensive list with worldwide coverage and international classification of formulation types. Biol. Control 43, 237-256 (2007).

9. Blond, C. L. H., Ridgway, H. J., Brownbridge, M. \& Chapman, R. B. Non-host larvae negatively impact persistence of the entomopathogen Beauveria bassiana in soil. Invertebr. Pathol. 156, 19-28 (2018).

10. Shapiro-Ilan, D. I. \& Brown, I. Earthworms as phoretic hosts for Steinernema carpocapsae and Beauveria bassiana: Implications for enhanced biological control. Biol. Control 66, 41-48 (2013).

11. Aira, M., Pérez-Losada, M. \& Domínguez, J. Microbiome dynamics during cast ageing in the earthworm Aporrectodea caliginosa. Appl. Soil. Ecol. 139, 56-63 (2019).

12. Riley, H., Pommeresche, R., Eltun, R., Hansen, S. \& Korsaeth, A. Soil structure, organic matter and earthworm activity in a comparison of cropping systems with contrasting tillage, rotations, fertilizer levels and manure use. Agr. Ecosyst. Environ. 124, 275-284 (2008).

13. Cortez, J. \& Bouché, M. Chemical composition of epidermial mucus from Allolobophora chaetophora (Oligochaeta: Lumbricidae). Comptes Rendus de l'Academie des Sciences Serie 3 Sciences de la Vie 305, 207-210 (1987).

14. Chaudhari, P. S. \& Bhattacharjee, G. Capacity of various experimental diets to support biomass and reproduction of Perionyx excavatus. Bioresour. Technol. 82, 147-150 (2002).

15. Prem-U-Domkit, K., Muangman, T., Klungsupya, P., Chantsavang, S. \& Kubera, A. Bioactivities of crude mucus proteins from Eudrilus eugeniae (African night crawler) and Perionyx excavatus (Blue worm). Eur. Rev. Med. Pharmacol. Sci. 21, 361-368 (2017).

16. Wang, C., Sun, Z., Liu, Y., Zhang, X. \& Xu, G. A novel antimicrobial vermipeptide family from earthworm Eisenia fetida. Eur. J. Soil Biol. 43, 127-134 (2007).

17. Heredia, R. et al. Autofluorescence as a tool to study mucus secretion in Eisenia foetida. Comp. Biochem. Physiol. 151, 407-414 (2008).

18. Zhang, D. et al. Earthworm epidermal mucus: Rheological behavior reveals drag-reducing characteristics in soil. Soil Tillage Res. 158, 57-66 (2016).

19. Huang, K. \& Xia, H. Role of earthworms' mucus in vermicomposting system: Biodegradation tests based on humification and microbial activity. Sci. Total Environ. 610, 703-708 (2018).

20. Wang, C., Sun, Z., Zheng, D. \& Liu, X. Function of mucilaginous secretions in the antibacterial immunity system of Eisenia fetida. Pedobiologia 54, 57-62 (2011).

21. Boyer, J., Reversat, G., Lavelle, P. \& Chabanne, A. Interactions between earthworms and plant-Parasitic nematodes. Eur. J. Soil Biol. 59, 43-47 (2013).

22. Chelkha, M. et al. Cutaneous excreta of the earthworm Eisenia fetida (Haplotaxida: Lumbricidae) might hinder the biological control performance of entomopathogenic nematodes. Soil Biol. Biochem. 141, 107-691 (2020).

23. Xiong, Q., Xie Y. P., Xue, J. L., Fan, R. J. \& Li, J. Observation and identification of strain TST05. In Entomopathogenic Fungi of Carposina sasakii and Their Application. (ed. Zhang, Z.H), 25-28(China Agricultural Science and Technology Press, 2015).

24. Xiong, Q. et al. Morphological and ultrastructural characterization of Carposina sasakii larvae (Lepidoptera: Carposinidae) infected by Beauveria bassiana (Ascomycota: Hypocreales: Clavicipitaceae). Micron 44, 303-311 (2013).

25. Xiong, Q., Wang, X., Zhu, Y. M., Cao, T. W. \& Xue, J. L. Compatibility of seven chemical pesticides with Beauveria bassiana strain TST05. Plant Prot. 38, 108-112 (2012).

26. Li, J. et al. Virulence of the five strains of entomopathogenic fungi infected on the larvae of Carposina sasakii. Acta Phytophylacica Sin. 39, 549-555 (2012).

27. Wang, W. P. Atrijuglans moth occurrence and control techniques. Technol. Dev. Enterp. 28, 30-30 (2009).

28. Wang, Y. et al. Infestation experiment of Atrijuglans hetaohei Yang larvae with the two strains of Beauveria bassiana. J. Shanxi Agric. Sci. 44, 662-665 (2016).

29. Lacey, L. A. et al. Insect pathogens as biological control agents: Back to the future. J. Invertebr. Pathol. 132, 1-41 (2015).

30. Yu, F. et al. Earthworm mucus interfere in the behavior and physiology of bacterial-feeding nematodes. Appl. Soil. Ecol. 143, $107-115$ (2019).

31. Salmon, S. \& Ponge, J. F. Earthworm excreta (mucus and urine) affect the distribution of springtails in forest soils. Biol. Fertil. Soils 34, 304-310 (2001).

32. Jaronski, S.T. Soil ecology of the entomopathogenic ascomycetes: a critical examination of what we (think) we know. In Use of Entomopathogenic Fungi in Biological Pest Management (ed. Maniana, K., Ekesi, S.) 91-144 (Research Signpost, 2008).

33. Zimmerman, G. The Galleria bait method for detection of entomopathogenic fungi in soil. J. Appl. Entomol. 102, 213-215 (1986).

34. Meyling, N. V. \& Eilenberg, J. Ecology of the entomopathogenic fungi Beauveria bassiana and Metarhizium anisopliae in temperate agroecosystems: Potential for conservation biological control. Biol. Control. 43, 145-155 (2007).

35. Zhang, S., Hu, F. \& Li, H. Effects of earthworm mucus and amino acids on cadmium subcellular distribution and chemical forms in tomato seedlings. Bioresour. Technol. 100, 4041-4046 (2009).

36. Stabili, L. \& Pagliara, P. Effect of zinc on lysozyme-like activity of the seastar Marthasterias glacialis (Echinodermata, Asteroidea) mucus. J. Invertebr. Pathol. 100, 189-192 (2009).

37. Wang, C. et al. Earthworm polysaccharide and its antibacterial function on plant-pathogen microbes in vitro. Eur. J. Soil Biol. 43, 135-142 (2007).

38. Pedrini, N., Crespo, R. \& Juarez, M. P. Biochemistry of insect epicuticle degradation by entomopathogenic fungi. Comp. Biochem. Physiol. 146, 124-137 (2007).

39. St. Leger, R. S., Cooper, R. M. \& Charnley, A. K. Cuticle-degrading enzymes of entomopathogenic fungi: cuticle degradation in vitro by enzymes from entomopathogens. J. Invertebr. Pathol. 47, 167-177 (1986).

40. Pelizza, S. A. et al. Virulence and enzymatic activity of three new isolates of Beauveria bassiana (Ascomycota: Hypocreales) from the South American locust Schistocerca cancellata (Orthoptera: Acrididae). J. King Saud Univ.-Sci. 32, 44-47 (2020).

41. Gu, C. X. et al. Characterization of the endothiapepsin-like protein in the entomopathogenic fungus Beauveria bassiana and its virulence effect on the silkworm, Bombyx mori. J. Invertebr. Pathol. 169, 107-277 (2020).

42. Kim, S. et al. Upregulation of cellulase activity and mRNA levels by bacterial challenge in the earthworm Eisenia andrei, supporting the involvement of cellulases in innate immunity. Biochem. Biophys. Res. Commun. 521, 15-18 (2020).

43. Wang, X., Chang, L. \& Sun, Z. J. Differential expression of genes in the earthworm Eisenia fetida following exposure to escherichia coli O157:h7. Dev. Comp. Immunol. 35, 525-529 (2011).

44. Dvořák, J., Roubalová, R., Procházková, P., Rossmann, P. \& Bilej, M. Sensing microorganisms in the gut triggers the immune response in Eisenia andrei earthworms. Dev. Comp. Immunol. 57, 67-74 (2016).

45. Cai, G. G. Studies of 23 Beauveria bassiana Strain Biological Characteristics. J. Fujian For. Sci. Technol. 3, 6-10 (2005). 
46. St. Leger, R. S., Charnley, A. K. \& Cooper, R. M. Characterization of cuticle-degrading proteases produced by the entomopathogen Metarhizium anisopliae. Arch. Biochem. Biophys. 253, 221-232 (1987).

47. Silva, W. O. B., Mitidieri, S., Schrank, A. \& Vainstein, M. H. Production and extraction of an extracellular lipase from the entomopathogenic fungus Metarhizium anisopliae. Process. Biochem. 40, 321-326 (2005).

\section{Acknowledgements}

The authors would like to thank the School of life sciences of Shanxi University for all the support it has provided for this research. In addition, the authors thank the Shanxi Science (Grant No. 20130311011-3), Technology Key Project (in Agriculture) of China (Grant No. 20140311017-6), and Science and Technology Innovation Project of Shanxi Education Department (Grant No. 2019L0065) for their funding.

\section{Author contributions}

X.B.Z., Y.P.X., and W.L.L. wrote the main manuscript text. X.B.Z., Y.P.X., W.L.L. and Y.F.Z. prepared Figs. 1, 2, 3, 4, 5 and 6. X.B.Z., Y.P.X., W.L.L., Y.F.Z., and Z.M.R. analyzed the data. All authors reviewed the manuscript.

\section{Competing interests}

The authors declare no competing interests.

\section{Additional information}

Correspondence and requests for materials should be addressed to Y.X.

Reprints and permissions information is available at www.nature.com/reprints.

Publisher's note Springer Nature remains neutral with regard to jurisdictional claims in published maps and institutional affiliations.

(c) (i) Open Access This article is licensed under a Creative Commons Attribution 4.0 International License, which permits use, sharing, adaptation, distribution and reproduction in any medium or format, as long as you give appropriate credit to the original author(s) and the source, provide a link to the Creative Commons licence, and indicate if changes were made. The images or other third party material in this article are included in the article's Creative Commons licence, unless indicated otherwise in a credit line to the material. If material is not included in the article's Creative Commons licence and your intended use is not permitted by statutory regulation or exceeds the permitted use, you will need to obtain permission directly from the copyright holder. To view a copy of this licence, visit http://creativecommons.org/licenses/by/4.0/.

(C) The Author(s) 2021 